\title{
On A Homework Problem of Larry Horn's
}

\author{
Francis Jeffry Pelletier \\ Simon Fraser University
}

Andrew Hartline
Simon Fraser University

\section{Introduction}

Larry Horn is justifiably famous for his work on the semantics of the English conjunction or and both its relationship to the formal logic truth functions $\vee$ and @ ("inclusive" and "exclusive" disjunction respectively ${ }^{1}$ ) and its relationship to the ways people employ or in natural discourse. These interests have been present since his 1972 dissertation, where he argued for a "scalar implicature-based" account of many of these relationships as opposed to a presuppositional account. They have surfaced in his "Greek Grice" paper (Horn 1973) as well as in his Negation book (Horn 1989) and his recent "Border Wars" paper (Horn, forthcoming) where he defends the position that there are two types of implicatures at work here: Qimplicatures based on Grice's first maxim of Quantity ("Say Enough") and R-implicatures based on Grice's second maxim of Quantity ("Don't Say Too Much"). In a nutshell, the idea is that when a speaker employs a sentence with a disjunction, the meaning (that is, the semantic value) of the or is inclusive. With careful and judicious use of the Q- and R-implicatures, Larry's theory allows the hearer (often) to infer that the speaker wanted to convey an exclusive disjunction.

Despite various claims in the literature that these implicatures are inadequate for the tasks for which they are devised (and there is more to the overall theory than merely the derivation of an intended-to-convey exclusive $o r$ from a semantically-valued inclusive $o r$ in context), certainly Larry's theory is a baseline to which any serious alternative must respond.

Not surprisingly then, issues surrounding or also show up in classes that Larry teaches.... specifically, in his semantics and pragmatics courses. In this paper we will take up one set of questions Larry has assigned as homework in various iterations of these classes. These questions all concern or, and are related to the issues discussed in the works mentioned above. Now, some

\footnotetext{
${ }^{1}$ Larry prefers '@' as a symbolization of exclusive or, because $v$ is sometimes claimed to come from Latin vel, and therefore the exclusive or should come from Latin aut... and "thus" be @. (It should be noted that Larry does not like either of these associations, but “one is as good as the other". And @ is much easier to use in email than $\oplus$, which is another popular choice.)
} 
of Larry's questions are easy and some of them are hard (technical terms). Our intent here, after discussing why the hard ones are hard, is to focus entirely on the easy ones. The specific easy questions Larry asks are in fact very easy...even though some scholars might not know the answers immediately off the top of their head. But behind the easy part of the easy questions are some very interesting considerations that are not at all well-known by scholars interested in the logic of the connectives. They should be; and we will investigate these topics. But before we begin with Larry's homework, there is a little background that needs to be brought out. It is the sort of thing that Larry would have already discussed before the homework was assigned.

\section{Background}

One theme that informs many writers' works on or is the issue of "inclusive vs. exclusive" senses/uses/meanings/... of or in natural English. A number of writers have weighed in on this issue, so that by now the consensus - at least among the cogniscenti - is that the semantic meaning of the natural English or is an inclusive truth function. (Pelletier 1977, Gazdar 1977, McCawley 1993, Jennings 1994, as well as Horn in the places cited above-and Larry is fond of pointing to earlier scholars from past centuries who have made the same point). Of course the use of or in natural English has to be accounted for in some other way, since the use of or often is exclusive. Some of the candidates for this use are people's informal expectations (Pelletier), Gricean implicatures (Grice, Horn), relevance-theoretic explicatures (Sperber \& Wilson 1986), or the historical development of a cluster of related concepts (Jennings). [An attempt at trying to distinguish all the different cases where people, including children, somehow arrive at an exclusive understanding of a sentence, is given in the psycholinguistic study of Noveck, et al 2002].

A background assumption of all this literature is that the fundamental semantic meaning of or is a truth-function; that is, the truth value of a complex sentence formed with or can be computed effectively by applying some function to the truth values of its component parts. Given the background assumption that it is some truth function, there are only two plausible candidates for the semantics of $o r$ : 
TABLE 1: Inclusive or $(\mathrm{v})$

\begin{tabular}{cc||c}
$\mathrm{P}$ & $\mathrm{Q}$ & $(\mathrm{P} \vee \mathrm{Q})$ \\
$\mathrm{T}$ & $\mathrm{T}$ & $\mathrm{T}$ \\
$\mathrm{T}$ & $\mathrm{F}$ & $\mathrm{T}$ \\
$\mathrm{F}$ & $\mathrm{T}$ & $\mathrm{T}$ \\
$\mathrm{F}$ & $\mathrm{F}$ & $\mathrm{F}$
\end{tabular}

TABLE 2: Exclusive or (@)

\begin{tabular}{cc||c}
$\mathrm{P}$ & $\mathrm{Q}$ & $(\mathrm{P} @ \mathrm{Q})$ \\
$\mathrm{T}$ & $\mathrm{T}$ & $\mathrm{F}$ \\
$\mathrm{T}$ & $\mathrm{F}$ & $\mathrm{T}$ \\
$\mathrm{F}$ & $\mathrm{T}$ & $\mathrm{T}$ \\
$\mathrm{F}$ & $\mathrm{F}$ & $\mathrm{F}$
\end{tabular}

Given this understanding - that or amounts to the truth-functional inclusive disjunction in its "literal", semantic import, but that the sentences that are thus generated can somehow convey a truth-functional exclusive disjunction - a crucial issue for such a theory becomes one of how the first row of TABLE 1 can somehow be ignored, and replaced by the first row of TABLE $2 \ldots .$. in ordinary discourse. Various of the mechanisms proposed in the literature have been mentioned above, and much of Larry's renown is due to his account of this process.

\section{Larry's Hard Questions (Which we will Ignore)}

All of Larry's hard questions concern the mechanism for converting the truth-functional inclusive $o r$ to a truth-functional exclusive $o r$, in context. As we remarked above, Larry's contribution is to combine a Gricean approach in terms of implicatures with a general theory of scaler values, and use this as a way for a hearer to predict when a given occurrence of or in a speaker's mouth should be understood exclusively. Larry's theory has not always been given unreserved praise, for instance in this homework question from McCawley (1993: 324):

Horn (1989:225) argues that or usually conveys "exclusive $o r$ " as a result of conversational implicature: if a speaker utters a sentence $A$ or $B$, he chose to say or rather than and, and he thus conveys that $\mathrm{A}$ and $\mathrm{B}$ are not both true, since if they were, cooperativity would have demanded that he say so. Show that this argument is fallacious: that if this reasoning is applied to the full range of orconjoining, the implicature generated by the speaker's choice of or rather than and will not in general agree with exclusive or.

The sort of topics in "the full range of or-conjoining" are cases where or is given three or more arguments, cases where one disjunct implies or implicates another, and certain puzzling cases of the implicature's applicability given a negated $o r$.

Larry's hard homework problems concern issues such as these. In addition, they concern the details of how argumentation would work in cases that are more complex than the usual toy problems mentioned in the literature...especially cases where there are multiple interacting implicatures. These are indeed very hard problems, and so opaque are they on Larry's theory 
that they have given rise to alternatives such as Relevance Theoretic accounts (Sperber \& Wilson 1986). In a fine piece of irony, these cases seem even harder to solve on these types of accounts than on Larry's, even though they gave rise to the new accounts in the first place.

As we said, we are going to skip over entirely these hard homework problems, and turn our attention to more tractable issues, although in the end we will return to a brief discussion of just what this process should strive to accomplish.

\section{Larry's Easy Problems}

The first two of Larry's easy problems ask:

(1) What does ((P@Q)@R) mean? (What does this formula "say"?).

(2) Write a truth table for $((\mathrm{P} @ \mathrm{Q}) @ \mathrm{R})$.

Most students will reflexively say that the formula means that "exactly one of the three disjuncts is true." And they will write down a truth table with just three T's in the final column, corresponding to the three rows where exactly one argument is T. However, if the student honestly writes the truth table, rather than just filling in the rows with what he or she thinks the answer is, the result will be:

TABLE 3: Three-argument exclusive or

\begin{tabular}{ccc||cc|}
$\mathrm{P}$ & $\mathrm{Q}$ & $\mathrm{R}$ & $(\mathrm{P} @ \mathrm{Q})$ & $((\mathrm{P} @ \mathrm{Q}) @ \mathrm{R})$ \\
$\mathrm{T}$ & $\mathrm{T}$ & $\mathrm{T}$ & $\mathrm{F}$ & $\mathrm{T}$ \\
$\mathrm{T}$ & $\mathrm{T}$ & $\mathrm{F}$ & $\mathrm{F}$ & $\mathrm{F}$ \\
$\mathrm{T}$ & $\mathrm{F}$ & $\mathrm{T}$ & $\mathrm{T}$ & $\mathrm{F}$ \\
$\mathrm{T}$ & $\mathrm{F}$ & $\mathrm{F}$ & $\mathrm{T}$ & $\mathrm{T}$ \\
$\mathrm{F}$ & $\mathrm{T}$ & $\mathrm{T}$ & $\mathrm{T}$ & $\mathrm{F}$ \\
$\mathrm{F}$ & $\mathrm{T}$ & $\mathrm{F}$ & $\mathrm{T}$ & $\mathrm{T}$ \\
$\mathrm{F}$ & $\mathrm{F}$ & $\mathrm{T}$ & $\mathrm{F}$ & $\mathrm{T}$ \\
$\mathrm{F}$ & $\mathrm{F}$ & $\mathrm{F}$ & $\mathrm{F}$ & $\mathrm{F}$ \\
& & & &
\end{tabular}

As can be seen, the answer to the Larry's question of what this formula says is: "The formula is true just in case either: exactly one of $\mathrm{P}, \mathrm{Q}$, and R is true, or else all three are true."

Although it is not on Larry's homeworks, a natural question to ask is what makes students reflexively think that the sentence asserts that exactly one of the three disjuncts is true. Here's why. The following argument is used in very many textbooks when the inclusive or is discussed. 
The inclusive or truth function is associative [i.e., $((\mathrm{P} \vee \mathrm{Q}) \vee \mathrm{R}) \Leftrightarrow(\mathrm{P} \vee(\mathrm{Q} \vee \mathrm{R}))$ ] so the internal parentheses can be dropped - the formula is equivalent in either disambiguation - and so we can simply write $(P \vee Q \vee R)$. Furthermore, $\vee$ is symmetric [i.e., $(\mathrm{P} \vee \mathrm{Q}) \Leftrightarrow(\mathrm{Q} \vee \mathrm{P})]$ and thus the disjuncts could be written in any order. Putting associativity and symmetry together allows us to write disjunctions in "prefix form" (sometimes called "quantificational form"): $v(P, Q)$ and $v(P, Q, R)$ and $\vee(P, Q, R, S)$, etc., and the order of the arguments does not matter.

The prenex form makes $v$ appear to be a variable-adicity operator (it can take an arbitrary number of sentence arguments in any order), and it always means that "at least one of the arguments is true." But, the textbooks say, it should be realized that this variable-adicity with sameness of meaning is due ultimately to the associativity and symmetry of the binary $v$ operator.

It seems to us that our students are employing the same argument with respect to @. After all, @ is symmetric $[(\mathrm{P} @ \mathrm{Q}) \Leftrightarrow(\mathrm{Q} @ \mathrm{P})]$ and as TABLE 4 shows, it is also associative.

TABLE 4: Three disjunct exclusive or

\begin{tabular}{ccc||cccc}
$\mathrm{P}$ & $\mathrm{Q}$ & $\mathrm{R}$ & $(\mathrm{P} @ \mathrm{Q})$ & $((\mathrm{P} @ \mathrm{Q}) @ \mathrm{R})$ & $(\mathrm{Q} @ \mathrm{R})$ & $(\mathrm{P} @(\mathrm{Q} @ \mathrm{R}))$ \\
$\mathrm{T}$ & $\mathrm{T}$ & $\mathrm{T}$ & $\mathrm{F}$ & $\mathrm{T}$ & $\mathrm{F}$ & $\mathrm{T}$ \\
$\mathrm{T}$ & $\mathrm{T}$ & $\mathrm{F}$ & $\mathrm{F}$ & $\mathrm{F}$ & $\mathrm{T}$ & $\mathrm{F}$ \\
$\mathrm{T}$ & $\mathrm{F}$ & $\mathrm{T}$ & $\mathrm{T}$ & $\mathrm{F}$ & $\mathrm{T}$ & $\mathrm{F}$ \\
$\mathrm{T}$ & $\mathrm{F}$ & $\mathrm{F}$ & $\mathrm{T}$ & $\mathrm{T}$ & $\mathrm{F}$ & $\mathrm{T}$ \\
$\mathrm{F}$ & $\mathrm{T}$ & $\mathrm{T}$ & $\mathrm{T}$ & $\mathrm{F}$ & $\mathrm{F}$ & $\mathrm{F}$ \\
$\mathrm{F}$ & $\mathrm{T}$ & $\mathrm{F}$ & $\mathrm{T}$ & $\mathrm{T}$ & $\mathrm{T}$ & $\mathrm{T}$ \\
$\mathrm{F}$ & $\mathrm{F}$ & $\mathrm{T}$ & $\mathrm{F}$ & $\mathrm{T}$ & $\mathrm{T}$ & $\mathrm{T}$ \\
$\mathrm{F}$ & $\mathrm{F}$ & $\mathrm{F}$ & $\mathrm{F}$ & $\mathrm{F}$ & $\mathrm{F}$ & $\mathrm{F}$
\end{tabular}

Applying the reasoning used in the inclusive or case we should be allowed to conclude that putting symmetry together with associativity allows us to write disjunctions in prefix form: $@(P, Q)$ and $@(P, Q, R)$ and $@(P, Q, R, S)$, etc., where the order of the arguments does not matter. The prefix form makes@ appear to be a variable-adicity operator, taking an arbitrary number of sentence arguments in any order, and it always means that "exactly one of the arguments is true."

But what the case of @ really shows is that either the general argument form is wrong (one cannot make any generalizations about what properties complex sentences will have merely from the ability to use a prefix form) or else the specific generalization is wrong (one can make generalizations from the ability to use a prefix form, but the relevant generalization is not that "at least one disjunct is true" in the v case and is not that "exactly one disjunct is true" in the @ 
case). The correct answer is the second of these options, and we will come back to that issue below. This point has been noted by some few authors previously (Reichenbach 1947: 45-47; Pelletier 1977: 71; McCawley 1993: 128-130; Jennings 1994: 6-7); and although Reichenbach, McCawley, and Jennings have indicated what the correct generalization is in the present case, none of them has given a general account of why this is so. Before we get into this last issue, though, let us return to Larry's easy problems.

(3) Given the above truth table for @(P,Q,R), what happens with four arguments to @, i.e., to @(P,Q,R,S)?

(4) What is the relevant generalization for $n$, i.e., for $@\left(\mathrm{P}_{1}, \mathrm{P}_{2}, \ldots \mathrm{P}_{\mathrm{n}}\right)$ ?

Some lazy students will try to generalize from their experience with the three-disjunct exclusive or. Of these lazy students, some will generalize that "either exactly one disjunct is true or else they all are true", while other of them will generalize that "either exactly one disjunct is true or three of them are true." The more cautious or diligent student will write out the truth table for $@(P, Q, R, S)$. We do this in steps, by writing the tables for @ $(P, Q)$ and @ $(R, S)$, and then joining them by @. (As we remarked above, @ is associative and symmetric, so the order of operations does not matter).

TABLE 5: Four-disjunct exclusive or

\begin{tabular}{cccc||ccc|}
$\mathrm{P}$ & $\mathrm{Q}$ & $\mathrm{R}$ & $\mathrm{S}$ & $(\mathrm{P} @ \mathrm{Q})$ & $(\mathrm{R} @ \mathrm{~S})$ & $((\mathrm{P} @ \mathrm{Q}) @(\mathrm{R} @ \mathrm{~S}))(=@(\mathrm{P}, \mathrm{Q}, \mathrm{R}, \mathrm{S}))$ \\
$\mathrm{T}$ & $\mathrm{T}$ & $\mathrm{T}$ & $\mathrm{T}$ & $\mathrm{F}$ & $\mathrm{F}$ & $\mathrm{F}$ \\
$\mathrm{T}$ & $\mathrm{T}$ & $\mathrm{T}$ & $\mathrm{F}$ & $\mathrm{F}$ & $\mathrm{T}$ & $\mathrm{T}$ \\
$\mathrm{T}$ & $\mathrm{T}$ & $\mathrm{F}$ & $\mathrm{T}$ & $\mathrm{F}$ & $\mathrm{T}$ & $\mathrm{T}$ \\
$\mathrm{T}$ & $\mathrm{T}$ & $\mathrm{F}$ & $\mathrm{F}$ & $\mathrm{F}$ & $\mathrm{F}$ & $\mathrm{F}$ \\
$\mathrm{T}$ & $\mathrm{F}$ & $\mathrm{T}$ & $\mathrm{T}$ & $\mathrm{T}$ & $\mathrm{F}$ & $\mathrm{T}$ \\
$\mathrm{T}$ & $\mathrm{F}$ & $\mathrm{T}$ & $\mathrm{F}$ & $\mathrm{T}$ & $\mathrm{T}$ & $\mathrm{F}$ \\
$\mathrm{T}$ & $\mathrm{F}$ & $\mathrm{F}$ & $\mathrm{T}$ & $\mathrm{T}$ & $\mathrm{T}$ & $\mathrm{F}$ \\
$\mathrm{T}$ & $\mathrm{F}$ & $\mathrm{F}$ & $\mathrm{F}$ & $\mathrm{T}$ & $\mathrm{F}$ & $\mathrm{T}$ \\
$\mathrm{F}$ & $\mathrm{T}$ & $\mathrm{T}$ & $\mathrm{T}$ & $\mathrm{T}$ & $\mathrm{F}$ & $\mathrm{T}$ \\
$\mathrm{F}$ & $\mathrm{T}$ & $\mathrm{T}$ & $\mathrm{F}$ & $\mathrm{T}$ & $\mathrm{T}$ & $\mathrm{F}$ \\
$\mathrm{F}$ & $\mathrm{T}$ & $\mathrm{F}$ & $\mathrm{T}$ & $\mathrm{T}$ & $\mathrm{T}$ & $\mathrm{F}$ \\
$\mathrm{F}$ & $\mathrm{T}$ & $\mathrm{F}$ & $\mathrm{F}$ & $\mathrm{T}$ & $\mathrm{F}$ & $\mathrm{T}$ \\
$\mathrm{F}$ & $\mathrm{F}$ & $\mathrm{T}$ & $\mathrm{T}$ & $\mathrm{F}$ & $\mathrm{F}$ & $\mathrm{F}$ \\
$\mathrm{F}$ & $\mathrm{F}$ & $\mathrm{T}$ & $\mathrm{F}$ & $\mathrm{F}$ & $\mathrm{T}$ & $\mathrm{T}$ \\
$\mathrm{F}$ & $\mathrm{F}$ & $\mathrm{F}$ & $\mathrm{T}$ & $\mathrm{F}$ & $\mathrm{T}$ & $\mathrm{T}$ \\
$\mathrm{F}$ & $\mathrm{F}$ & $\mathrm{F}$ & $\mathrm{F}$ & $\mathrm{F}$ & $\mathrm{F}$ & $\mathrm{F}$
\end{tabular}

We see that @ $(\mathrm{P}, \mathrm{Q}, \mathrm{R}, \mathrm{S})$ is true when exactly one of the four components is true and when exactly three of the four components are true, and false otherwise. The lazy students who 
generalized the wrong way have now learned that the answer to these sorts of questions is that either one or three disjuncts are true, and the lazy students who generalized to this answer will be reinforced. Even the more cautious student might also jump to this generalization, now that there are two instances.

These lazy students, who have that generalization before their minds based on @ $(\mathrm{P}, \mathrm{Q}, \mathrm{R})$ and $@(\mathrm{P}, \mathrm{Q}, \mathrm{R}, \mathrm{S})$, might now conclude in Larry's easy question (4) that $@\left(\mathrm{P}_{1}, \mathrm{P}_{2}, \ldots \mathrm{P}_{\mathrm{n}}\right)$ is true when exactly one of $\mathrm{P}_{1}, \mathrm{P}_{2}, \ldots \mathrm{P}_{\mathrm{n}}$ are true and when exactly three of $\mathrm{P}_{1}, \mathrm{P}_{2}, \ldots \mathrm{P}_{\mathrm{n}}$ are true, and is false otherwise. The more diligent or cautious student might first write a truth table for @(P,Q,R,S,T) and see that it is true when exactly one of P,Q,R,S,T are true and when exactly three of $\mathrm{P}, \mathrm{Q}, \mathrm{R}, \mathrm{S}, \mathrm{T}$ are true and when exactly five of $\mathrm{P}, \mathrm{Q}, \mathrm{R}, \mathrm{S}, \mathrm{T}$ are true, and is false otherwise... as TABLE 6 shows.

TABLE 6: Five-disjunct exclusive $o r$

\begin{tabular}{|c|c|c|c|c|c|c|c|c|}
\hline$\underline{P}$ & $\mathrm{Q}$ & $\mathrm{R}$ & $S$ & $\mathrm{~T}$ & $(\mathrm{P} @ \mathrm{Q})$ & $(\mathrm{R} @ \mathrm{~S})$ & $((\mathrm{P} @ \mathrm{Q}) @(\mathrm{R} @ \mathrm{~S}))$ & $@(\mathrm{P}, \mathrm{C}$ \\
\hline $\mathrm{T}$ & $\mathrm{T}$ & $\mathrm{T}$ & $\mathrm{T}$ & $\mathrm{T}$ & $\mathrm{F}$ & $\mathrm{F}$ & $\mathrm{F}$ & $\mathrm{T}$ \\
\hline $\mathrm{T}$ & $\mathrm{T}$ & $\mathrm{T}$ & $\mathrm{T}$ & $\mathrm{F}$ & $\mathrm{F}$ & F & F & $\mathrm{F}$ \\
\hline $\mathrm{T}$ & $\mathrm{T}$ & $\mathrm{T}$ & $\mathrm{F}$ & $\mathrm{T}$ & $\mathrm{F}$ & $\mathrm{T}$ & $\mathrm{T}$ & $\mathrm{F}$ \\
\hline $\mathrm{T}$ & $\mathrm{T}$ & $\mathrm{T}$ & F & $\mathrm{F}$ & F & $\mathrm{T}$ & $\mathrm{T}$ & $\mathrm{T}$ \\
\hline $\mathrm{T}$ & $\mathrm{T}$ & $\mathrm{F}$ & $\mathrm{T}$ & $\mathrm{T}$ & $\mathrm{F}$ & $\mathrm{T}$ & $\mathrm{T}$ & $\mathrm{F}$ \\
\hline $\mathrm{T}$ & $\mathrm{T}$ & $\mathrm{F}$ & $\mathrm{T}$ & $\mathrm{F}$ & $\mathrm{F}$ & $\mathrm{T}$ & $\mathrm{T}$ & $\mathrm{T}$ \\
\hline $\mathrm{T}$ & $\mathrm{T}$ & $\mathrm{F}$ & $\mathrm{F}$ & $\mathrm{T}$ & $\mathrm{F}$ & $\mathrm{F}$ & $\mathrm{F}$ & $\mathrm{T}$ \\
\hline $\mathrm{T}$ & $\mathrm{T}$ & F & F & $\mathrm{F}$ & F & $F$ & F & $\mathrm{F}$ \\
\hline $\mathrm{T}$ & $\mathrm{F}$ & $\mathrm{T}$ & $\mathrm{T}$ & $\mathrm{T}$ & $\mathrm{T}$ & $\mathrm{F}$ & $\mathrm{T}$ & $\mathrm{F}$ \\
\hline $\mathrm{T}$ & $\mathrm{F}$ & $\mathrm{T}$ & $\mathrm{T}$ & $\mathrm{F}$ & $\mathrm{T}$ & $\mathrm{F}$ & $\mathrm{T}$ & $\mathrm{T}$ \\
\hline $\mathrm{T}$ & $\mathrm{F}$ & $\mathrm{T}$ & $\mathrm{F}$ & $\mathrm{T}$ & $\mathrm{T}$ & $\mathrm{T}$ & $\mathrm{F}$ & $\mathrm{T}$ \\
\hline $\mathrm{T}$ & $\mathrm{F}$ & $\mathrm{T}$ & $\mathrm{F}$ & $\mathrm{F}$ & $\mathrm{T}$ & $\mathrm{T}$ & F & $\mathrm{F}$ \\
\hline $\mathrm{T}$ & $\mathrm{F}$ & F & $\mathrm{T}$ & $\mathrm{T}$ & $\mathrm{T}$ & $\mathrm{T}$ & $\mathrm{F}$ & $\mathrm{T}$ \\
\hline $\mathrm{T}$ & $\mathrm{F}$ & $\mathrm{F}$ & $\mathrm{T}$ & $\mathrm{F}$ & $\mathrm{T}$ & $\mathrm{T}$ & $\mathrm{F}$ & $\mathrm{F}$ \\
\hline $\mathrm{T}$ & $\mathrm{F}$ & $\mathrm{F}$ & $\mathrm{F}$ & $\mathrm{T}$ & $\mathrm{T}$ & $\mathrm{F}$ & $\mathrm{T}$ & $\mathrm{F}$ \\
\hline $\mathrm{T}$ & $\mathrm{F}$ & $\mathrm{F}$ & $F$ & $\mathrm{~F}$ & $\mathrm{~T}$ & $\mathrm{~F}$ & $\mathrm{~T}$ & $\mathrm{~T}$ \\
\hline F & $\mathrm{T}$ & $\mathrm{T}$ & $\mathrm{T}$ & $\mathrm{T}$ & $\mathrm{T}$ & $\mathrm{F}$ & $\mathrm{T}$ & $\mathrm{F}$ \\
\hline $\mathrm{F}$ & $\mathrm{T}$ & $\mathrm{T}$ & $\mathrm{T}$ & $\mathrm{F}$ & $\mathrm{T}$ & $\mathrm{F}$ & $\mathrm{T}$ & $\mathrm{T}$ \\
\hline $\mathrm{F}$ & $\mathrm{T}$ & $\mathrm{T}$ & $\mathrm{F}$ & $\mathrm{T}$ & $\mathrm{T}$ & $\mathrm{T}$ & $\mathrm{F}$ & $\mathrm{T}$ \\
\hline F & $\mathrm{T}$ & $\mathrm{T}$ & $\mathrm{F}$ & $F$ & $\mathrm{~T}$ & $\mathrm{~T}$ & $\mathrm{~F}$ & $\mathrm{~F}$ \\
\hline $\mathrm{F}$ & $\mathrm{T}$ & F & $\mathrm{T}$ & $\mathrm{T}$ & $\mathrm{T}$ & $\mathrm{T}$ & F & $\mathrm{T}$ \\
\hline $\mathrm{F}$ & $\mathrm{T}$ & $\mathrm{F}$ & $\mathrm{T}$ & $\mathrm{F}$ & $\mathrm{T}$ & $\mathrm{T}$ & $\mathrm{F}$ & $\mathrm{F}$ \\
\hline $\mathrm{F}$ & $\mathrm{T}$ & $\mathrm{F}$ & $\mathrm{F}$ & $\mathrm{T}$ & $\mathrm{T}$ & $\mathrm{F}$ & $\mathrm{T}$ & $\mathrm{F}$ \\
\hline $\mathrm{F}$ & $\mathrm{T}$ & $\mathrm{F}$ & $\mathrm{F}$ & $\mathrm{F}$ & $\mathrm{T}$ & $\mathrm{F}$ & $\mathrm{T}$ & $\mathrm{T}$ \\
\hline $\mathrm{F}$ & $\mathrm{F}$ & $\mathrm{T}$ & $\mathrm{T}$ & $\mathrm{T}$ & $\mathrm{F}$ & $\mathrm{F}$ & $\mathrm{F}$ & $\mathrm{T}$ \\
\hline $\mathrm{F}$ & $\mathrm{F}$ & $\mathrm{T}$ & $\mathrm{T}$ & $\mathrm{F}$ & $\mathrm{F}$ & $\mathrm{F}$ & $\mathrm{F}$ & $\mathrm{F}$ \\
\hline $\mathrm{F}$ & $\mathrm{F}$ & $\mathrm{T}$ & $\mathrm{F}$ & $\mathrm{T}$ & $\mathrm{F}$ & $\mathrm{T}$ & $\mathrm{T}$ & $\mathrm{F}$ \\
\hline $\mathrm{F}$ & $\mathrm{F}$ & $\mathrm{T}$ & $\mathrm{F}$ & $\mathrm{F}$ & $\mathrm{F}$ & $\mathrm{T}$ & $\mathrm{T}$ & $\mathrm{T}$ \\
\hline F & $\mathrm{F}$ & F & $\mathrm{T}$ & $\mathrm{T}$ & F & $\mathrm{T}$ & $\mathrm{T}$ & $\mathrm{F}$ \\
\hline F & $\mathrm{F}$ & F & $\mathrm{T}$ & $\mathrm{F}$ & F & $\mathrm{T}$ & $\mathrm{T}$ & $\mathrm{T}$ \\
\hline $\mathrm{F}$ & $\mathrm{F}$ & $\mathrm{F}$ & $\mathrm{F}$ & $\mathrm{T}$ & $\mathrm{F}$ & $\mathrm{F}$ & $\mathrm{F}$ & $\mathrm{T}$ \\
\hline F & $\mathrm{F}$ & $\mathrm{F}$ & $\mathrm{F}$ & $\mathrm{F}$ & F & $\mathrm{F}$ & $\mathrm{F}$ & $\mathrm{F}$ \\
\hline
\end{tabular}


(The last column is generated by @-ing the second-last column with T. As mentioned, the symmetry and associativity of @-conjunction means that any order or grouping of evaluation generates the same answer.) Such a student might correctly generalize to the claim that $@\left(\mathrm{P}_{1}, \mathrm{P}_{2}, \ldots \mathrm{P}_{\mathrm{n}}\right)$ is true if and only if an odd number of $\mathrm{P}_{1}, \mathrm{P}_{2}, \ldots \mathrm{P}_{\mathrm{n}}$ are true, and is false otherwise.

This is the answer to Larry's question (4), and brings us to the end of Larry's easy homework. But there are a number of loose ends remaining, and questions that this whole set of exercises has brought up.

\section{Is There Another Way to Get a Generalized Exclusive or? (Not so Easy)}

The fact that different numbers of arguments to embedded iterations of @ give rise to different interpretations of the resulting sentences suggests that there is not a unique connective @ that is once and for all given a single semantic interpretation to use in all sentences where it occurs. For, in addition to knowing what the disjuncts say (i.e., whether they are true or false), you have to know how many of them are true. You don't have to know which are true and which are false, only how many... a very peculiar truth-function.

McCawley (1993) uses the prefix form of $\vee$ and $\wedge($ and $)$ in his syntax on the grounds that this syntax comports better with natural language syntax than the binary connectives that logicians have introduced. He interprets them as "at least one of the following is true" and "all the following are true". But as we have seen, if we wanted a prefix connective for exclusive $o r$, we could not use iterations of binary @, and instead would have to invent a whole new connective $\mathrm{v}_{\mathrm{e}}$ that meant "exactly one of the following is true". Using a rather convoluted argument, McCawley (1993: 128-130) claims that since $v_{\mathrm{e}}$ cannot be eliminated in favor of iterations of the binary @, and instead must be taken as a wholly new connective that must be prefix, this forms another argument in favor of understanding $\vee$ and $\wedge$ as prefix quantifiers. (Of course, we might just as easily take it as "another argument against exclusive or, or at least against generalized exclusive $o r$ '. But let's not pause over that.) 
So we can't use (iterations) of @ for this purpose ${ }^{2}$, and this is McCawley's underlying rationale for saying that Larry's mechanism won't work “in the full range of or-conjoining", because the result of applying the mechanism converts v into @, and @ is not the right connective to generate $\mathrm{v}_{\mathrm{e}}$. McCawley did not think to wonder whether a new ternary connective $\oplus^{3}$ could be used to define $v_{\mathrm{e}}$. The sentence $\oplus^{3}(\mathrm{P}, \mathrm{Q}, \mathrm{R})$, using this new connective, says that exactly one of the three disjuncts is true. And we might wonder whether there is some way to say that exactly four are true by judicious embedding of some $\oplus^{3}$-formula inside another $\oplus^{3}$ formula. For example, might $\oplus^{3}\left(\oplus^{3}(\mathrm{P}, \mathrm{Q}, \mathrm{R}), \oplus^{3}(\mathrm{Q}, \mathrm{R}, \mathrm{S}), \mathrm{S}\right)$ do the trick? Or if not this one, then some other one? And, can we define the binary @ - which we might as well call $\oplus^{2}$ - using just $\oplus^{3}$ ? And having done this, is there a way to define all the other $\oplus^{n}$ formulas, for all $n$ 's? This would be to define McCawley's $v_{\mathrm{e}}{ }^{3}$

Some aspects of this question are easy; for example, binary exclusive or can be straightforwardly defined in terms of $\oplus^{3}$, and we will do that in the next section. We can also see easily that the formula suggested above will not do the trick of defining $\oplus^{4}(\mathrm{P}, \mathrm{Q}, \mathrm{R}, \mathrm{S})$; for, if all four sentence letters are true then $\oplus^{3}(P, Q, R)$ and $\oplus^{3}(Q, R, S)$ will be false, and hence $\oplus^{3}\left(\oplus^{3}(\mathrm{P}, \mathrm{Q}, \mathrm{R}), \oplus^{3}(\mathrm{Q}, \mathrm{R}, \mathrm{S}), \mathrm{S}\right)$ will be true because exactly one of the disjuncts, namely $\mathrm{S}$, is true. What is not so easily seen is that no simple embedding of $\oplus^{3}$ inside $\oplus^{3}$ can do the trick all by itself, although it is a consequence of the remark made in the last footnote.

\section{How to define generalized exclusive or using $\oplus^{3}$}

Although no simple embedding will do the trick, there is in fact a "natural" way to construct the relevant formula. We will start with some preliminary definitions, and then move on to the

\footnotetext{
${ }^{2}$ Of course, for any specific $n$ there is some formula of classical logic which will express that "exactly one of the following $n$ disjuncts is true". For, given that we have a functionally complete set of connectives (such as negation and conjunction, or negation and inclusive or, etc.) then any specific semantic requirement can be written by some formula. And if one allows "variables" in the syntax, one can even give a formula that expresses the general claim: $\vee_{\mathrm{e}}\left(\mathrm{P}_{1}, \mathrm{P}_{2}, \ldots \mathrm{P}_{\mathrm{n}}\right)=_{\mathrm{df}} \vee\left(\mathrm{P}_{1}, \mathrm{P}_{2}, \ldots \mathrm{P}_{\mathrm{n}}\right) \wedge \sim\left(\mathrm{P}_{\mathrm{i}} \wedge \mathrm{P}_{\mathrm{j}}\right)$ for all $i, j \leq n$ and $i \neq j$.

But the question being asked is whether there is some sort of analogue of $\vee$ or @ that can do the trick by itself.

${ }^{3}$ There will still be unexpected results of embedding such a connective inside itself. Consider $\mathrm{v}_{\mathrm{e}}\left(\mathrm{v}_{\mathrm{e}}\left(\mathrm{P}_{1}, \mathrm{P}_{2}, \ldots \mathrm{P}_{\mathrm{n}}\right), \mathrm{v}_{\mathrm{e}}\left(\mathrm{Q}_{1}, \mathrm{Q}_{2}, \ldots \mathrm{Q}_{\mathrm{k}}\right), \mathrm{R}\right)$.

If more than one of the $P$ 's are true, and more than one of the $Q$ 's are true, then $v_{e}\left(P_{1}, P_{2}, \ldots P_{n}\right)$ and $v_{e}\left(Q_{1}, Q_{2}, \ldots Q_{k}\right)$ are both false. So, if $\mathrm{R}$ is true then the entire formula is true. But it has become true even though at least five of the atomic arguments are true. So, the property of "being true of exactly one of the disjuncts" is not "passed upwards" to the wider-scope $v_{\mathrm{e}}$ (it is not "upwards inherited", in the terminology of Pelletier \& Martin, 1990).
} 
$\oplus^{4}$ case. After describing how that formula works, we turn our attention to the more general case of defining $\oplus^{\mathrm{n}}$, for any $n$. This last is always done using $\oplus^{\mathrm{n}-1}$ in a certain fixed manner, and so the whole process is "inductive" or "compositional".

McCawley's (1993) conclusions seemed to be that since (binary) exclusive or, @, couldn't yield a "real" (i.e., generalized) exclusive or $\left(\mathrm{v}_{\mathrm{e}}\right)$, we need to postulate this generalized connective as a primitive. In fact, he suggests, since we can't even define any of the $\oplus^{3}, \oplus^{4}$, etc., and so we don't have a chance of giving a general method to define $\oplus^{\mathrm{n}}$, which might serve as a surrogate for $\mathrm{v}_{\mathrm{e}}$.

But what these investigations really showed is merely that the binary @ won't correctly generalize. In fact $\oplus^{3}$ does generalize; that is, there exists a "natural" way to construct ever more complex formulas that use only $\oplus^{3}$ and define the truth functions $\oplus^{\mathrm{n}}$, for any $n$ - where $\oplus^{\mathrm{n}}\left(\mathrm{P}_{1}, \mathrm{P}_{2}, \ldots \mathrm{P}_{\mathrm{n}}\right)$ is an $\mathrm{n}$-ary formula that is true if exactly one of $\mathrm{P}_{1}, \mathrm{P}_{2}, \ldots \mathrm{P}_{\mathrm{n}}$ are true and is false otherwise. Of course, it is to be expected that the definition or generation of these connectives will be more complex than the similar generalization of binary inclusive $v$ to $v^{n}-$ which is achieved by merely defining

$$
v^{n}\left(P_{1}, P_{2}, \ldots P_{n}\right)={ }_{d f}\left(v^{n-1}\left(P_{1}, P_{2}, \ldots P_{n-1}\right) \vee P_{n}\right)
$$

for $n \geq 3$. [Relying on the associativity of $\mathrm{v}$ ].

$\oplus^{3}$ is actually a very interesting connective, and is able to define many different truth functions. As for its limitations: $\oplus^{3}$ is F-preserving, that is, when all of its input arguments are false, then it too yields the value false. This is a property that is "upwards inherited" - any complex formula made up only of F-preserving connectives will also be false in the row where all atomic inputs are false. ${ }^{4}$ Therefore, $\oplus^{3}$ cannot by itself be used to define a formula that has $\mathrm{T}$ in the last row of its truth table (last row in the standard ordering of rows: all the input subformulas are false). In particular, this means that none of the connectives $\sim, \supset, \downarrow$ (nor), $\uparrow$ (nand) can be defined using only $\oplus^{3}$. And thus unlike $\uparrow$ and $\downarrow$, it does not by itself form a functionally complete set of connectives. Still, there are many connectives that can be defined by using $\oplus^{3}$ only, including $\oplus^{\mathrm{n}}$, for all $n$, as we will see. This being the case, $\oplus^{3}$ can quite plausibly be thought of as a basis for a "real" exclusive or in McCawley's sense.

\footnotetext{
${ }^{4}$ The proof of this can be found in Pelletier \& Martin (1990).
} 
Here's how. We first define a few preliminary things.

$$
\begin{array}{llll}
\mathbf{F} & =_{\mathrm{df}} & \oplus^{3}(\mathrm{P}, \mathrm{P}, \mathrm{P}) & {[\text { the constant False }]} \\
(\mathrm{P} @ \mathrm{Q}) & =_{\mathrm{df}} & \oplus^{3}(\mathrm{P}, \mathrm{Q}, \mathbf{F}) & \text { [the binary exclusive } \text { or }] \\
(\mathrm{P} \wedge \sim \mathrm{Q}) & =_{\mathrm{df}} & \oplus^{3}(\mathrm{P}, \mathrm{Q}, \mathrm{Q}) & \text { [the binary } \text { and-not connective] }
\end{array}
$$

As for the first, if $\mathrm{P}$ is true then there are three true inputs; but if it is false then there are none. In either case the resulting formula is false. In the second formula, the third argument is always false, so the truth value of the whole depends just on whether $\mathrm{P}$ and $\mathrm{Q}$ are true or false. If exactly one is true then the whole formula is true; and it is false otherwise. But this is just exclusive disjunction. As for the third formula, note first that it could never be true if $\mathrm{Q}$ is true, since then there would be at least two true arguments. So Q must be false. Hence, if it is true, this must be on account of P's being true. That is, $\mathrm{P}$ is true and $\mathrm{Q}$ is false: the binary and-not connective.

Now consider

$$
\left.\oplus^{3}((\mathrm{P} \wedge \sim \mathrm{Q}), \mathrm{R}, \mathrm{R}) \quad \text { [i.e., } \oplus^{3}\left(\oplus^{3}(\mathrm{P}, \mathrm{Q}, \mathrm{Q}), \mathrm{R}, \mathrm{R}\right)\right]
$$

This is identical to

$$
((\mathrm{P} \wedge \sim \mathrm{Q}) \wedge \sim \mathrm{R}),
$$

and generally we can easily define an extended $\mathrm{n}$-ary and-not connective $\wedge \sim \sim^{\mathrm{n}}\left(\mathrm{P}_{1}, \mathrm{P}_{2}, \ldots \mathrm{P}_{\mathrm{n}}\right)$ which is true if $\mathrm{P}_{1}$ is true and all of $\mathrm{P}_{2}, \ldots \mathrm{P}_{\mathrm{n}}$ are false, and is false otherwise.

Now let's consider the four formulas

$$
\wedge \sim^{4}(\mathrm{P}, \mathrm{Q}, \mathrm{R}, \mathrm{S}) \quad \wedge \sim^{4}(\mathrm{Q}, \mathrm{P}, \mathrm{R}, \mathrm{S}) \quad \wedge \sim^{4}(\mathrm{R}, \mathrm{P}, \mathrm{Q}, \mathrm{S}) \quad \wedge \sim^{4}(\mathrm{~S}, \mathrm{P}, \mathrm{Q}, \mathrm{R})
$$

Each of these formulas is true just in case its first argument is true and all the rest are false. Let's take the first three of them and embed them under $\oplus^{3}$ :

$$
\oplus^{3}\left(\wedge \sim^{4}(\mathrm{P}, \mathrm{Q}, \mathrm{R}, \mathrm{S}), \wedge \sim^{4}(\mathrm{Q}, \mathrm{P}, \mathrm{R}, \mathrm{S}), \wedge \sim^{4}(\mathrm{R}, \mathrm{P}, \mathrm{Q}, \mathrm{S})\right)
$$

By the truth table for $\oplus^{3}$, this formula is true just in case exactly one of the embedded formulas is true - that is, just in case exactly one of (a) P is true and Q,R,S are false, or (b) Q is true and $\mathrm{P}, \mathrm{R}, \mathrm{S}$ are false, or (c) $\mathrm{R}$ is true and $\mathrm{P}, \mathrm{Q}, \mathrm{S}$ are false, occurs. Finally, consider

$$
\oplus^{2}\left(\oplus^{3}\left(\wedge \sim^{4}(\mathrm{P}, \mathrm{Q}, \mathrm{R}, \mathrm{S}), \wedge \sim^{4}(\mathrm{Q}, \mathrm{P}, \mathrm{R}, \mathrm{S}), \wedge \sim^{4}(\mathrm{R}, \mathrm{P}, \mathrm{Q}, \mathrm{S})\right), \wedge \sim^{4}(\mathrm{~S}, \mathrm{P}, \mathrm{Q}, \mathrm{R})\right),
$$

where we have used binary exclusive or to disjoin (1) with $\wedge \sim^{4}(S, P, Q, R)$. Formula (2) is true just in case one of (a), (b), (c) or ( $\mathrm{S}$ is true and P,Q,R are false). But this means that formula (2) 
is true just in case exactly one of $\mathrm{P}, \mathrm{Q}, \mathrm{R}, \mathrm{S}$ are true and all the others are false. And this is precisely $\oplus^{4}$, defined entirely in terms of $\oplus^{3}$.

It is pretty easy to see that this method can be generalized to yield $\oplus^{\mathrm{n}}$, for any $n$. The idea is to use $\oplus^{\mathrm{n}-1}, \oplus^{2}$, and $\wedge \sim^{\mathrm{n}}$ to define $\oplus^{\mathrm{n}}$. We have already seen that $\oplus^{2}$ and $\wedge \sim^{\mathrm{n}}$ can be defined for any $n$, using only $\oplus^{3}$. We need only describe the way to generate $\oplus^{\mathrm{n}}$ given that we have $\oplus^{\mathrm{n}-1}, \oplus^{2}$, and $\wedge \sim^{\mathrm{n}}$. Since we have a way to say that exactly one of $n$ subformulas are true while all the others are false, let's look at this list of formulas:

$$
\begin{aligned}
& \wedge \sim\left(P_{1}, P_{2}, \ldots P_{n}\right) \\
& \wedge \sim\left(P_{2}, P_{1}, P_{3} \ldots P_{n}\right) \\
& \bullet \bullet \bullet \\
& \wedge \sim\left(P_{n-1}, P_{1}, \ldots, P_{n-2}, P_{n}\right) \\
& \wedge \sim\left(P_{n}, P_{1}, \ldots P_{n-1}\right)
\end{aligned}
$$

Each of these says that its first argument is true and all its others are false. Since we already have $\oplus^{\mathrm{n}-1}$ by hypothesis, we can use the first $n$ - 1 formulas on this list and say

$$
\oplus^{\mathrm{n}-1}\left(\wedge \sim^{\mathrm{n}}\left(\mathrm{P}_{1}, \mathrm{P}_{2}, \ldots \mathrm{P}_{\mathrm{n}}\right), \wedge \sim^{\mathrm{n}}\left(\mathrm{P}_{2}, \mathrm{P}_{1}, \mathrm{P}_{3} \ldots \mathrm{P}_{\mathrm{n}}\right), \ldots, \wedge \sim^{\mathrm{n}}\left(\mathrm{P}_{\mathrm{n}-1}, \mathrm{P}_{1}, \ldots, \mathrm{P}_{\mathrm{n}-2}, \mathrm{P}_{\mathrm{n}}\right)\right),
$$

thereby asserting that exactly one of the embedded formulas is true, i.e., that exactly one of $\mathrm{P}_{1}, \mathrm{P}_{2}, \ldots \mathrm{P}_{\mathrm{n}-1}$ is true while at the same time all the others are false, including $\mathrm{P}_{\mathrm{n}}$. We can now complete the definition by doing a binary exclusive or of this formula with the last formula on the list:

$$
\oplus^{2}\left(\oplus^{\mathrm{n}-1}\left(\wedge \sim^{\mathrm{n}}\left(\mathrm{P}_{1}, \mathrm{P}_{2}, \ldots \mathrm{P}_{\mathrm{n}}\right), \wedge \sim^{\mathrm{n}}\left(\mathrm{P}_{2}, \mathrm{P}_{1}, \mathrm{P}_{3} \ldots \mathrm{P}_{\mathrm{n}}\right), \ldots, \wedge \sim^{\mathrm{n}}\left(\mathrm{P}_{\mathrm{n}-1}, \mathrm{P}_{1}, \ldots, \mathrm{P}_{\mathrm{n}-2}, \mathrm{P}_{\mathrm{n}}\right)\right), \wedge \sim^{\mathrm{n}}\left(\mathrm{P}_{\mathrm{n}}, \mathrm{P}_{1}, \ldots \mathrm{P}_{\mathrm{n}-1}\right)\right),
$$

which is true if and only if one or the other (but not both) of the two embedded formulas are true. That is, it is true iff either (i) exactly one of $\mathrm{P}_{1}, \mathrm{P}_{2}, \ldots \mathrm{P}_{\mathrm{n}-1}$ are true and all the others (including $\mathrm{P}_{\mathrm{n}}$ ) are false, or (ii) $\mathrm{P}_{\mathrm{n}}$ is true and all of $\mathrm{P}_{1}, \mathrm{P}_{2}, \ldots \mathrm{P}_{\mathrm{n}-1}$ are false.

But that is precisely $\oplus^{n}\left(P_{1}, P_{2}, \ldots P_{n}\right)$ : the formula that says that exactly one of the $n$ disjuncts is true. And this in turn is McCawley's $\mathrm{v}_{\mathrm{e}}\left(\mathrm{P}_{1}, \mathrm{P}_{2}, \ldots \mathrm{P}_{\mathrm{n}}\right)$, the generalized exclusive $o r$.

\section{Concluding Remarks}

Larry's hard problems had asked for some mechanism to go from a "literal" inclusive or meaning of a sentence with a binary disjunction to an "implicated" exclusive or meaning of that binary disjunction. In the binary case, it seems pretty clear that there are various different 
mechanisms that will work, including Larry's favored Gricean inferences. In particular it is clear what the starting point is (an inclusive binary or truth function $v$, or $v^{2}$ as we call in when put in prefix form), and what the end point is (an exclusive or truth function @ , or $\oplus^{2}$ as we have called it when put in prefix form). Arguments concern only the issue of what the most plausible method is for the generation of that end point from that start point.

However, in the "full range of disjunctions" (as McCawley puts it) the start and finish are much less clear. Larry's easy problems (1) and (2) seem to show that, in the case of a threemember disjunction, one should not assume the start point is a set of two inclusive $v$ 's and that they each get converted to an exclusive @, so that we are left with a three member disjunction with each part being connected by @. For, this has the truth table of TABLE 3, while what we want is a three-place truth function that is true just in case exactly one of the disjunct is true - the truth function we called $\oplus^{3}$. It looks like Larry's mechanism (as well as the other mechanisms that have been suggested) fall prey to McCawley's objection.

But this was for the specific case of trying to generate $\oplus^{3}$ (and by implication, $\oplus^{\mathrm{n}}$ for higher values of $n$ ) from the @'s (which were in turn generated from v's by the hard mechanism). The considerations we mentioned show that this cannot be done: there is no way to define $\oplus^{3}$ in terms of @ alone. Our suggestion was that we should find some hard mechanism to convert $\mathrm{v}^{3}$ to $\oplus^{3}$, other than the faulty “convert each $\vee$ to a @ and then 'go prenex'." For, once one has $\oplus^{3}$, the generation of $\oplus^{\mathrm{n}}$ is algorithmic and does not call for any of the hard mechanisms. Larry would of course be free to keep his current mechanism that converts the binary $\vee$ to the binary @, rather than use the method described above that generated @ from $\oplus^{3}$. (After all, the mechanism given above for this generation did not use the same algorithmic method that was used to generate the $\oplus^{\mathrm{n}} \mathrm{s}$ for $\left.n>3\right)$.

So, that is a new hard problem for Larry's future semantics and pragmatics classes: Is there any Gricean hard method that will convert $\mathrm{v}^{3}$ to $\oplus^{3}$ ? 


\section{Bibliography}

Horn, L. (1972) On the Semantic Properties of Logical Operators in English. PhD dissertation, UCLA.

Horn, L. (1973) "Greek Grice: A Brief Survey of Proto-Conversational Rules in the History of Logic" CLS 9: 205-214.

Horn, L. (1989) A Natural History of Negation (Univ. Chicago Press: Chicago).

Horn, L. (forthcoming) "Border Wars: a Neo-Gricean Perspective" in K. Turner and K. von Heusinger (eds.) Where Semantics Meets Pragmatics. (Elsevier: Amsterdam)

Jennings, R. (1994) The Genealogy of Disjunction (Oxford UP: NY).

McCawley, J. (1993) Everything that Linguists Have Always Wanted to Know About Logic, $2^{\text {nd }}$ Edition (Univ. Chicago Press: Chicago).

Noveck, I., G. Chierchia, F. Chevaux, R. Guelminger, E. Sylvestre (2002) "Linguistic-Pragmatic Factors in Interpreting Disjunctions” Thinking and Reasoning 8: 297-326.

Pelletier, F.J. (1977) “Or” Theoretical Linguistics 4: 61-74.

Pelletier, F.J. \& N. Martin (1990) "Proving Post's Functional Completeness Theorem" Notre Dame Journal of Formal Logic 31: 462-475.

Reichenbach, H. (1947) Elements of Symbolic Logic (Free Press: NY). 